\title{
Recaudación fiscal, abasto y control del ganado en el Buenos Aires tardocolonial: los propios y arbitrios del Cabildo entre 1780 y 1820
}

\author{
Tax Collection, Supply and Control Cattle \\ in Colonial Buenos Aires: The propios \\ and arbitrios between 1780-1820
}

\author{
Antonio Facundo Galarza* \\ Universidad Nacional de Mar del Plata, Buenos Aires, Argentina, email: afgcuervo@hotmail.com
}

Resumen. Se aborda el problema de la recaudación de impuestos por parte del Ayuntamiento de la ciudad de Buenos Aires entre 1780 y 1820 (los llamados propios y arbitrios). Además, se identifican los principales ingresos y gastos del Cabildo y se intenta medir la carga fiscal del mismo sobre la población. Hago hincapié en la relevancia del ramo de derecho de corrales dentro de la estructura de ingresos, donde destaco la contradicción planteada entre las necesidades de abastecer de carne al mercado de la ciudad y los riesgos de establecer controles más estrictos sobre la propiedad del ganado vacuno. Busco demostrar que las autoridades de la época priorizaron la gobernabilidad antes que un mayor control sobre la propiedad del ganado, lo cual podía poner en riesgo el abasto de carne y el cobro de impuestos.

Palabras clave: recaudación de impuestos; peso fiscal; propiedad; abastecimiento.

Abstract: In the article is addressed the problem of tax collection by the municipality of the city of Buenos Aires between 1780 and 1820 (the so-called propios y arbitrios). Are identified the main revenue and expenditure of the council and it seeks to measure the tax burden on the population. In particular, it emphasizes the importance of corral tax in the income structure of the town council, and the contradiction arose between the needs of meat supply to the city market and risks of establishing tighter controls in concerning ownership of slaughtered animals. It seeks to show that the authorities of the time gave priority to governability rather than greater control over livestock ownership, which put at risk the supply of citadino meat and the collection of municipal taxes.

Key words: tax collection; tax burden; property; supplying.

Fecha de recibido: 17 de mayo de 2016. Fecha de aceptado: 26 de septiembre de 2016.

* Consejo Nacional de Investigaciones Científicas y Técnicas.

Am. Lat. Hist. Econ., may.-ago., 2017, pp. 7-34 | DOI: 10.18232/alhe.v24i2.789 


\begin{abstract}
El más recomendable derecho es el que funda la necesidad de que las ciudades o provincias se hallen siempre abastecidas de lo que es preciso para subsistencia, porque esta es la suprema Ley. Manuel Basavilbaso (1773), procurador general de Buenos Aires.
\end{abstract}

\title{
INTRODUCCIÓN
}

$\mathrm{L}$ as palabras del procurador general de Buenos Aires que preludian estas líneas pretenden ilustrar la centralidad que, a entender de las autoridades, poseía el abasto de alimentos a la ciudad de Buenos Aires a fines del siglo XVIII. En cierta forma, la afirmación de Basavilbaso daba cuenta de la primacía del avituallamiento citadino por sobre otros aspectos caros a los gobernantes de la época, como podían ser el cobro de impuestos y el control de la actividad ganadera, una de las más importantes de la región rioplatense. En esta línea, la investigación que a continuación se presenta versa sobre algunos de los problemas que el Ayuntamiento de la capital virreinal enfrentó en los tiempos tardocoloniales al momento de la recaudación impositiva. Será entonces argumento central de este trabajo el ilustrar cómo la necesidad de abastecer de alimentos -en particular de carne-, la premura por percibir mayores ingresos tributarios y los requerimientos por hacer respetar la propiedad del ganado vacuno se conjugaron de un modo particular en el Buenos Aires de fines del siglo XVIII y principios del XIX.

Una de las posibilidades que exhibe el estudio de este nivel local de la fiscalidad colonial -el de los cabildos- refiere a caracterizar las limitaciones y alcances que el reformismo borbón encontró en su afán de control de las finanzas de la monarquía. Este ha sido el itinerario descrito por los estudios sobre los presupuestos de los ayuntamientos ibéricos, los cuales han señalado la impronta centralista que desde inicios del siglo XVIII se intentó plasmar en el manejo de recursos locales en Valencia, Alicante y Cataluña, entre otras regiones (García, 1986). Más allá de la heterogeneidad mostrada por los diferentes escenarios provinciales ibéricos a fines del XVIII (Angulo, 2002), las investigaciones enfocadas en las finanzas municipales ponderan los cambios ocurridos a partir de 1760, cuando dio inicio un periodo de intento de saneamiento de las cuentas capitulares a partir de las políticas fiscales implementadas por Fernando VI y continuadas luego por Carlos III (García, 1986; Martínez, 1997). Según estos estudios, la imagen de un "municipio controlado" reflejaría el estado de situación de la mayoría de los ayuntamientos hispánicos. 
Aunque no necesariamente centrados en las finanzas municipales, a esta mirada que pondera la capacidad regia de intervenir en los escenarios fiscales locales se opone un conjunto de investigaciones más recientes que, en cambio, subrayan las dificultades de la corona en la consecución de objetivos centralizadores durante todo el siglo XVIII (Bertrand, Dubet, Dolbes y Torres, 2014; Dedieu, 2014; Dubet, 2010; Torres, 2013). Los autores argumentan que el intento de vigilancia, que significó la creación de la Contaduría General de Propios y Arbitrios, se tradujo en resultados mitigados, aunque es pertinente destacar que resultó exitosa en cuanto obligó a las oligarquías locales a negociar con el poder regio. ${ }^{1}$ En una línea similar, Torres (2013) plantea que hacia 1775 era notorio el avance de la corona sobre las finanzas de los cabildos, pero con fuertes limitaciones que le impidieron por ejemplo disponer de los fondos excedentes de los propios y arbitrios para solventar la guerra contra Gran Bretaña iniciada en 1779, tal como había sido uno de los objetivos reales. ${ }^{2}$

Para el caso americano, la lógica seguida por las investigaciones más recientes que versan sobre la fiscalidad local es similar a esta segunda línea de estudios sobre los casos ibéricos. En Nueva España -sin dudas el espacio mejor estudiado- el examen de la fiscalidad a nivel de los ayuntamientos también se enfoca en los intentos de avance regio sobre las cuentas capitulares, los cuales no sólo pretendían un mejoramiento de las exacciones, sino también propiciar una mayor injerencia de los funcionarios reales en los asuntos de las cajas. Para las investigaciones de Bustamante (2010), Celaya (2014) y Silva (2015) el manejo de los recursos de los cabildos novohispanos se habría constituido en un campo de negociación. Con resultados disímiles, las investigaciones ponderan las capacidades de los poderes locales de lograr espacios de negociación permanente pese a los avances centralizadores de la corona.

En cuanto al Río de la Plata, es poco lo que se sabe acerca de las finanzas municipales en tiempos coloniales y menos aún acerca del manejo administrativo-político de los recursos de los ayuntamientos, es decir, de sus propios y arbitrios. Si para el caso de Buenos Aires contamos con el excelente trabajo de reconstrucción de presupuestos y recopilación de normativas de Oscar Ensinck (1990), para otros cabildos rioplatenses apenas

\footnotetext{
1 "No significa que las oligarquías locales perdieran toda influencia pero se las obliga a negociar y justificarse. [...] Se trata de obligar a cada ciudad a preparar un estado de fondos y cargas anual validado por el Consejo de Castilla en su nueva Contaduría General de Propios y Arbitrios" (Bertrand, Dubet, Dolbes y Torres, 2014, p. 25).

${ }^{2}$ Torres $(2013$, p. 179) señala que la "extraordinaria contribución", antes que un aumento de presión fiscal era un intento de transferencia de caudales desde las arcas municipales a las de la tesorería real. Pretensión que se vio frustrada en la práctica por diversos motivos, entre ellos la capacidad de negociación de los poderes locales.
} 
conocemos algunos valores de sus fondos y gastos durante el periodo colonial. Tales son los casos de Mendoza (Santos, 1974) y Santa Fe (Ensinck, 1984) donde la mirada sobre los cabildos y sus finanzas es tangencial y esporádica. Trabajos valiosos en cuanto permiten un primer acercamiento a la problemática fiscal de los ayuntamientos, pero limitados en su análisis a la hora de elaborar un panorama de la dinámica tributaria de estas administraciones locales.

Para el virreinato rioplatense siguen brillando por su ausencia investigaciones que evidencien aspectos tales como el avance del reformismo borbón sobre los recursos de los ayuntamientos, los problemas para obtener ingresos que suplieran los gastos y las disputas (políticas) de poder asociadas a la dinámica fiscal -y su influencia en las recaudaciones- entre otras posibles inquietudes. El peso fiscal de los cabildos también es una vía de investigación que hasta aquí ha resultado poco explorada, no sólo para el Río de la Plata. ${ }^{3}$ Los debates en torno a las vinculaciones entre desempeño económico, instituciones y peso fiscal constituyen un campo historiográfico cada vez más roturado por las investigaciones sobre las economías latinoamericanas de los siglos XVIII y XIX. ${ }^{4}$ Sin embargo, en las estimaciones que estos trabajos recogen para caracterizar la evolución económica de largo plazo se destaca la ausencia de la figura de los ayuntamientos y su carga tributaria sobre la población.

En virtud de comenzar a llenar algunos de estos vacíos historiográficos, examinamos los propios y arbitrios del Cabildo de Buenos Aires entre 1780 y 1820 , se identifican los principales ingresos y erogaciones e intentamos reconstruir el peso fiscal que sobre la población porteña representaron los impuestos municipales. Prestamos especial atención al gravamen denominado "derecho de corrales" -arancel que recaía sobre el ganado ingresado en la ciudad, destinado al consumo de carne- a fin de caracterizar

\footnotetext{
${ }^{3}$ Así lo señala Sánchez (2011) en su estudio sobre el peso fiscal en México, básicamente centrado en la Real Hacienda "El otro componente básico de la fiscalidad en ambos periodos [el colonial y el republicano] el municipal, no cuenta con suficientes trabajos como para aportar una visión global" (p. 111). Sobre el Río de la Plata, el intento más reciente de medir la carga fiscal corresponde a Cuesta (2009) aunque su mirada se limita a los impuestos de la Caja de Buenos Aires y no a los del Ayuntamiento, como veremos más adelante.

${ }^{4}$ Sobre el tema, la bibliografía es extensa. A modo de resumen pueden señalarse los argumentos clásicos de Coatsworth (1990) y Engerman y Sokoloff (1999) quienes sostenían la existencia de pobres desempeños económicos de las economías latinoamericanas tras las independencias, originados principalmente en factores institucionales (respeto por la propiedad, exceso de carga fiscal, ausencia de mercados de capitales, entre otros). Nuevas perspectivas discuten estas ideas, sosteniendo un crecimiento moderado aunque no insignificante durante el siglo XIX y discutiendo el peso de la supuesta "herencia colonial" y de las guerras de independencia para las posibilidades de crecimiento de los nuevos países latinoamericanos. Sobre estas nuevas perspectivas, además de Sánchez (2011) y Márquez (2014) puede consultarse la obra de Llopis y Marichal (2009), especialmente los trabajos allí contenidos del propio Sánchez Santiró, Gelman y Dobado González.
} 
la evolución de su recaudación e identificar algunos de los problemas que la misma encontró en la práctica. Nos proponemos demostrar la existencia de una relación -y caracterizarla- entre la fiscalidad, las necesidades del abasto citadino y un aspecto que consideramos relevante en una región donde la producción ganadera se hallaba en expansión: el respeto por la propiedad del ganado vacuno. ${ }^{5}$

\section{El ganado en Buenos Aires a fines del siglo XViII: Algunos Datos}

Es sabido que la principal mercancía salida del puerto de Buenos Aires durante el periodo colonial no fueron los productos agropecuarios sino la plata potosina (Garavaglia, 1987). No obstante, los cueros vacunos representaron el bien exportable más importante producido en la jurisdicción de la capital virreinal, así como el consumo de carne citadino protagonizó un crecimiento sostenido entre fines del siglo XVIII y principios del XIX. Ambas variables explican el crecimiento que la actividad ganadera protagonizó en la región circundante al Río de la Plata (véanse cuadros 1 y 2).

Más allá de que las cifras de cueros exportados desde esta región continúan siendo objeto de debate historiográfico, investigaciones de referencia permiten dar cuenta del aumento de las actividades pecuarias en el ámbito bonaerense. ${ }^{6}$ Vale destacar que, en el caso de los cueros exportados, sólo una parte correspondía a producción de la campaña bonaerense y el resto provenía de otras regiones del litoral virreinal como Misiones, Paraguay, Entre Ríos y Santa Fe, entre otros. ${ }^{7}$

Lo que nos interesa es visibilizar un marco de producción pecuaria en crecimiento, en donde -como veremos- el asegurar el respeto por la propiedad del ganado se constituyó en una preocupación relevante para las autoridades de la época. Nos permitimos adelantar que, tal como señala

${ }^{5}$ Aunque la evolución de la concepción jurídica de derecho de propiedad no constituye nuestro objeto de estudio, podemos señalar que la consolidación de una noción restrictiva de propiedad en sentido liberal o privada fue un proceso largo que abarcó buena parte del siglo XIX y que se vio marcada por cambios en la cultura jurídica así como implicó la supresión de prácticas consuetudinarias que iban a contramano de esta concepción. Para un panorama sobre estos temas, remitimos a Barriera (2010) y Congost (2011).

${ }^{6}$ Sobre el volumen de la producción de cueros y su exportación en el Río de la Plata, el debate ha sido prolífico. Mientras Garavaglia (1999) presenta datos más austeros, los trabajos más recientes estiman que las cantidades exportadas por el puerto de la capital virreinal durante el siglo XVIII habrían sido mayores. Los trabajos consultados sobre el tema son los citados a pie del cuadro 2 .

${ }^{7}$ Garavaglia (1999, p. 221) estima en 230000 los cueros producidos en Buenos Aires en 1790 y en 163000 para el año de 1791. Camarda (2015, p. 130), por su parte, estima un promedio anual de 500000 cueros salidos del complejo portuario rioplatense entre 1779 y 1799 , correspondiendo unos 220000 a Montevideo y 275000 al puerto de Buenos Aires. 


\section{CUADRO 1. BUENOS AIRES: ABASTO ANUAL DE VACUNOS (EN CABEZAS DE GANADO)}

$A \tilde{n} o$

1722

1748

1783-1787

1788-1792

$1812-1816$

$1822-1824$
Número de cabezas

18000

$25000-30000$

36178

46052

72718

73874

Nota: Entre 1744 y 1810 la tasa de crecimiento poblacional en la ciudad de Buenos Aires fue de 3.69 (de 11600 a 42872 habitantes) en tanto que la tasa de crecimiento del consumo de ganado entre 1748 y 1812 fue de 2.42. Es decir que el mercado urbano de la carne creció en términos nominales pero a ritmos menores que la expansión poblacional. Los datos de población pueden verse en Cuesta (2006, p. 211).

Fuente: Garavaglia (1999, p. 218).

CUADRO 2. BUENOS AIRES: ESTIMACIÓN DE EXPORTACIONES ANUALES DE CUEROS (EN PROMEDIO ANUAL)

\begin{tabular}{lccc}
\hline Periodo & Garavaglia & Jumar, Camarda & Rosal y Schmit \\
$1756-1778$ & 130000 & 124609 & 85444 \\
$1779-1796$ & 272500 & 281094 & 279221 \\
$1815-1820$ & 676000 & s. d. & 874239 \\
\hline
\end{tabular}

Fuentes: elaboración propia con base en Camarda (2015), Garavaglia (1999), Jumar (2000) y Rosal y Schmit (2004).

Jorge Gelman (2005), a fines del periodo colonial la prédica tanto de funcionarios como de comerciantes "apunta al afianzamiento de la propiedad privada de tierras y ganados, a la supresión de todo lo que atente contra su pleno y libre usufructo" (Gelman, 2005, p. 468). Esa inquietud por limitar prácticas consideradas ilegales en el manejo del ganado vacuno no sólo remitía al momento de su introducción en los mercados, sino tal como veremos, también al de su reproducción y circulación en los diferentes partidos que componían el hinterland bonaerense. 


\section{Y EL DERECHO DE CORRALES}

El Ayuntamiento de Buenos Aires, como el del resto de las ciudades del imperio español, percibía ciertos impuestos para solventar sus gastos, conocidos como propios y arbitrios. En 1795, desde la Contaduría General de Propios y Arbitrios - perteneciente a la Real Hacienda- se dictó un reglamento (elaborado con base en lo recaudado entre 1789-1795) mediante el cual se buscó imponer al Cabildo pautas de cuánto debía recaudarse por cada impuesto y cómo debían gastarse los fondos. Entre los propios se contaban los ramos de derecho de corrales, pontazgo (para mantener puentes), alquileres (de propiedades del Cabildo), venta de sal, derecho de pulperías, derechos de plaza (pagados por puestos de venta de alimentos en la plaza y la recova) y casa de gallos. Los arbitrios consistían en botijas y barriles (impuesto al consumo de bebidas), mulas, pregonería (sobre ventas en subasta pública) e impuesto a mercachifles, billares y canchas. ${ }^{8}$

En la gráfica 1 puede observarse la participación de las principales imposiciones percibidas por el cuerpo capitular sobre el total recaudado entre 1780 y 1820 . El nuevo impuesto representó 33\%, seguido del derecho de corrales con 16\% sobre el total. El gravamen sobre la venta de pan alcanzó 14\% mientras que el extraordinario sobre pan y carne llegó a 10\%, aunque su existencia se limitó al periodo 1815-1819. Algo similar ocurrió con el nuevo impuesto, establecido en 1807 como un recurso extraordinario. ${ }^{9}$ Con estos datos, la relevancia del derecho de corrales -caro a nuestros objetivos- resulta aún mayor para los años 1780-1806 (véase gráfica 3).

En cuanto a los gastos, se dividían en cuatro clases (véanse cuadros 3 y 4). La primera estaba destinada al pago de sueldos, mientras que los de segunda clase eran más reducidos y correspondían a alquileres por la utilización de ciertas propiedades. Los de tercera clase estaban representados por las fiestas y celebraciones de variado tipo que el Ayuntamiento debía llevar adelante. Finalmente, los llamados gastos extraordinarios o de cuarta clase remitían a gastos por construcciones edilicias, mantenimiento de la

${ }^{8}$ Para un detalle minucioso de cada propio y arbitrio, así como de los tipos de gastos pautados en el reglamento de 1795, véase Ensinck (1990, pp. 295-306).

${ }^{9}$ Como señala Ensinck (1990, p. 368) este arancel se impuso a los vinos, aguardientes y azúcares introducidos en la capital con el fin de solventar gastos de guerra por la reconquista de la ciudad. Inicialmente creado de manera temporal por el virrey a pedido del Cabildo, el nuevo impuesto se mantuvo durante los años siguientes dadas las urgencias presupuestarias: "meditaron los SS. se imponga durante la guerra una contribución en los azúcares, vinos y aguardientes por no ser renglones de primera necesidad; Y que para ello se solicite permiso del Excelentísimo Señor Virrey [...] con la condición precisa de que cesando la guerra deberá cesar la contribución". Acuerdo del 22 de septiembre de 1806. Libro LXI, f. 33, p. 307, Acuerdos del Extinguido Cabildo de Buenos Aires (en adelante AECBA). 

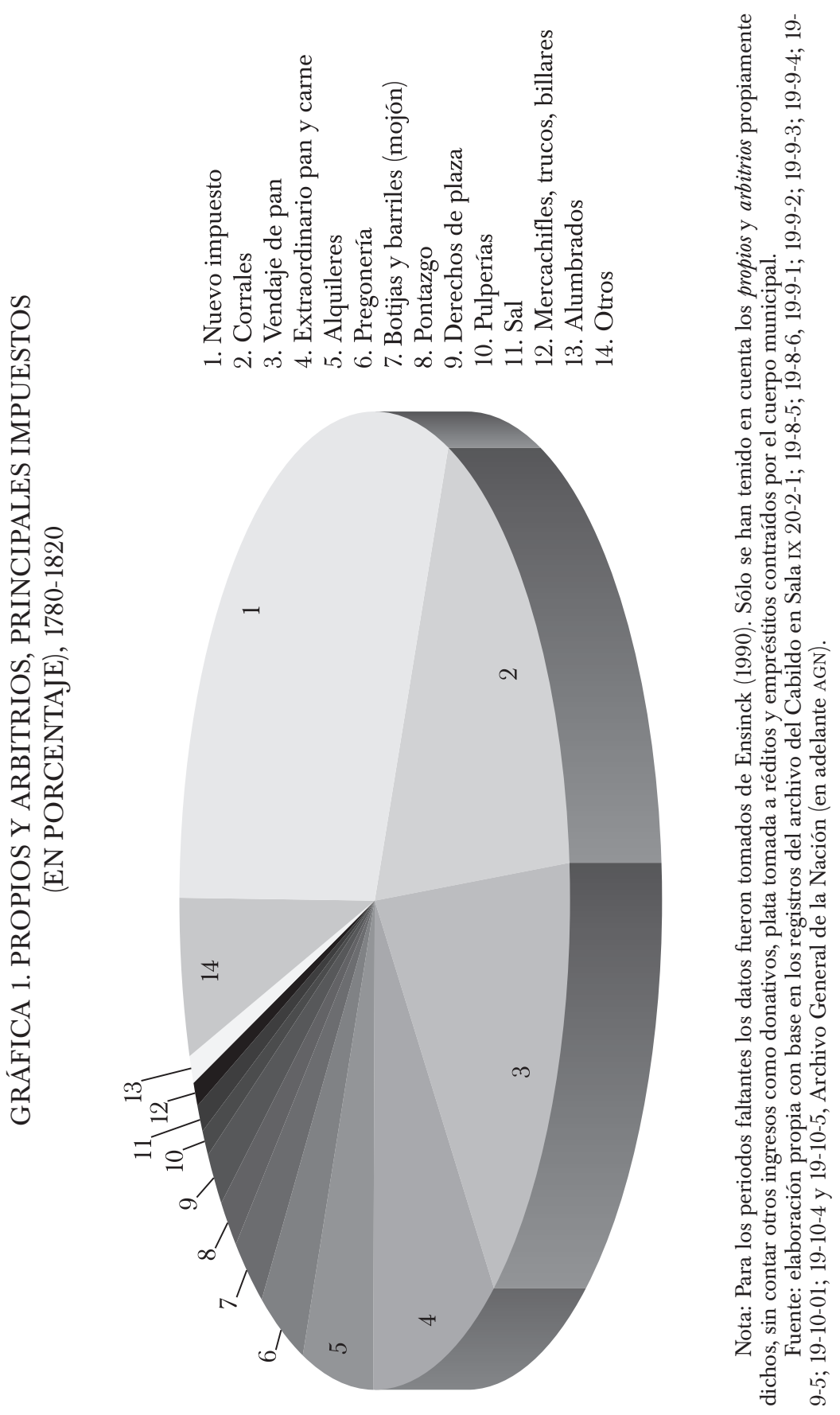
cárcel, alquileres de coche, costos por causas judiciales, y cualquier otra erogación que no entrara en los ítems anteriores.

Los criterios de gasto estipulados en 1795 mediante reglamento de la Junta Superior, lejos estuvieron de cumplimentarse (véanse cuadros 3 y 4). Por el contrario, la abrumadora mayoría de las erogaciones del Cabildo correspondió a extraordinarios, tendencia que se acentuó a partir de 18051806, cuando se multiplicaron los gastos militares. Como veremos, esto permitió un manejo más autónomo del presupuesto por parte del cuerpo capitular. La urgencia permitió y justificó la captación de nuevos recursos, retroalimentando una tendencia al crecimiento de las recaudaciones de propios y arbitrios que, según la bibliografía especializada, se caracterizó por un aumento ralentizado durante todo el siglo XVIII y un aceleramiento desde inicios de la centuria siguiente. ${ }^{10}$

Hemos intentado medir la carga fiscal que el Ayuntamiento representaba para la población porteña: según nuestros cálculos, entre 1780 y 1800 el peso fiscal permaneció estable entre uno y dos reales per cápita, mientras que a partir de 1801 comenzó a elevarse (véase cuadro 5). ${ }^{11}$ Los datos con los que contamos muestran que la población citadina no llegó a duplicarse entre 1778 y 1810 (pasó de 24363 a 42872 habitantes) mientras que hacia 1820 contaba con cerca de 55000 habitantes, por lo que el incremento exponencial de la recaudación aventajó por mucho al crecimiento poblacional.

Mientras que el aumento fiscal de 1804 se explica por la subida del arancel sobre el ganado ingresado en los corrales, el peso tributario se elevó sostenidamente a partir de 1807, cuando el Ayuntamiento debió afrontar ingentes gastos militares, incluso supliendo erogaciones que correspondían a la Hacienda Real. ${ }^{12}$

La caída de la recaudación en 1810 debido al recambio de los administradores de impuestos, como detallaremos más adelante, explica el

10 "El aumento sostenido se produce a partir de los primeros años del siglo XIX. De los 6070 pesos de recursos que el cabildo tenía en 1794, pasamos a los 26725 en 1800, 157894 en 1805 y a 320768 en 1821. El aumento fue de cincuenta veces en veintiséis años. Claro que hubo años de ingresos extraordinarios y egresos también extraordinarios, como los años 1806 y 1807" (Ensinck, 1990, pp. 12-13).

${ }^{11}$ Cuesta (2009, pp. 54-55) estima una fuerte presión fiscal en Buenos Aires en 1790, cercana a los diez pesos, aun mayor que la existente en Inglaterra que para esa fecha era de 9.5. Sus inferencias son resultante de los impuestos de la Caja Real y no de los fondos recabados por el Ayuntamiento, los que sumados arrojarían una carga fiscal de 10.2 pesos. Sin embargo, como el propio Cuesta señala, la dificultad de tomar en cuenta los impuestos de la Caja porteña es que una parte recaía sobre la población del virreinato y no sólo de la jurisdicción de Buenos Aires.

${ }^{12}$ Aun si contamos la población de la campaña, la carga del fisco arroja valores altos para 1807 (1.2), 1808 (2.1) y 1809 (1.7) para descender a cuatro reales en 1810 y retomar la tendencia ascendente en 1811 (en general en valores cercanos a 50\% de lo expresado en el cuadro 4 para toda la década). 
CUADRO 3. PROPIOS Y ARBITRIOS, GASTO ESTIPULADO EN 1795

\begin{tabular}{lrc}
\hline Clase & Monto & Porcentaje \\
& & \\
Primera & 6060 & 54 \\
Segunda & 1635 & 15 \\
Tercera & 988 & 9 \\
Cuarta & 2500 & 22 \\
\hline
\end{tabular}

Fuente: elaboración propia a partir de Ensinck (1990).

CUADRO 4. TOTAL GASTOS, 1795-1804

\begin{tabular}{lrc}
\hline Clase & Monto & Porcentaje \\
& & \\
Primera & 19665 & 13 \\
Segunda & 6300 & 4 \\
Tercera & 9317 & 6 \\
Cuarta & 118641 & 77 \\
\hline
\end{tabular}

Fuente: elaboración propia a partir de Ensinck (1990).

descenso de la carga fiscal en ese año, que parece más bien una excepción dentro de un lapso de un creciente peso tributario del Cabildo que inicia en 1807 para recién desacelerarse diez años después. En la segunda década del siglo, fue entre 1815 y 1816 cuando ese peso se hizo sentir con mayor fuerza, superando los seis pesos, para iniciar un paulatino descenso hasta 1820.

El incremento del peso tributario durante el decenio 1807-1817 se explica en buena parte gracias a que, si bien en teoría los gastos de guerra debían ser afrontados por la Real Hacienda ${ }^{13}$ durante las invasiones inglesas la defensa de la ciudad fue solventada en gran medida con fondos

${ }^{13}$ Con ese fin la Real Hacienda cobraba el impuesto municipal de guerra, ramo que servía para el pago de gastos militares de frontera. En ocasiones, el Cabildo solicitaba se le adelantasen fondos de este ramo que luego reintegraba "hallándose el Cabildo exhausto de fondos y en urgente precisión de emprehender la expedición de salinas, ocurrió más de una vez a su Superior Gobierno a fin de que se le subministrase dinero del dicho ramo de Guerra". Nota del Cabildo 9 de agosto de 1791, en Ensinck (1990, p. 127). Diversos trabajos han abordado el estudio de la caja de Buenos Aires, señalando su dependencia del situado potosino y su estructura de gastos e ingresos. Una puesta al día bibliográfica sobre el tema en Galarza (2015). 
Am. Lat. Hist. Econ., año 24, núm. 2, mayo-agosto, 2017, pp. 7-34

\section{CUADRO 5. CARGA FISCAL DEL AYUNTAMIENTO PORTEÑO (EN PESOS DE OCHO REALES) 1801-1820}

\begin{tabular}{llll}
\hline Año & Carga & Año & Carga \\
1801 & 0.4 & 1811 & 3 \\
1802 & 0.2 & 1812 & 1.6 \\
1803 & 0.3 & 1813 & 2.7 \\
1804 & 1 & 1814 & 2.4 \\
1805 & 0.6 & 1815 & 4 \\
1806 & 0.6 & 1816 & 6.4 \\
1807 & 2.2 & 1817 & 2.5 \\
1808 & 3.6 & 1818 & 2.5 \\
1809 & 3 & 1819 & 2.1 \\
1810 & 1 & 1820 & 1.3 \\
\hline
\end{tabular}

Nota: Los datos impositivos son los mismos de la gráfica 1, correspondientes a recaudación de ramos que recaían sobre la población ( $\sin$ créditos, transferencias, ni existencias anteriores, etc.). Hemos decidido no contabilizar los donativos voluntarios y sólo tener en cuenta los gravámenes extraordinarios. (2006).

Fuente: Los datos de población de la ciudad de Buenos Aires fueron extraídos de Cuesta

municipales, gracias a que se incluyeron las erogaciones militares en los llamados "gastos extraordinarios" o de cuarta clase. ${ }^{14}$ Con esta maniobra presupuestaria ocurrió como con el "nuevo impuesto": una solución de excepción que en adelante se convirtió en norma, manteniéndose durante la década de 1810, lo que explicaría los altos niveles de la carga fiscal de esa década.

Cabe destacar que a fines de la colonia, el Ayuntamiento no sólo corrió con gastos que eran propios de la Caja Real, sino que también realizó préstamos para suplir las urgencias de la misma. ${ }^{15}$ Algo similar ocurrió

${ }^{14}$ En 1807, los gastos se dividieron del siguiente modo: primera clase, 7756 pesos; segunda clase, 19 106; tercera clase, 2862 y cuarta clase 250257 pesos. En estos últimos, encontramos por ejemplo 33500 pagados a oficiales, soldados y marineros de la Real Marina en concepto de gratificación, 7865 pesos pagados a tropa voluntaria en auxilio de Montevideo y 10500 pagados a Cornelio Saavedra para la compra de uniformes del Cuerpo de Patricios, entre otros variados gastos con fines militares. Véase Archivo de Propios del Cabildo, 1807, Sala IX, 19-10-01, ff. 18, $24 \mathrm{v}$ y 25 , AGN.

${ }^{15}$ Según Amaral (2011, pp. 413-415) en 1807 el Cabildo suplió a la Caja de Buenos Aires 580000 pesos, reintegrándosele 469504 . En 1808 volvió a prestar 509 000, pero sólo se le reintegraron 51 972, mientras que en 1809 no realizó suplementos y se le devolvieron 274310 . Aunque también el Cabildo recibió préstamos - de menor valor- de la Hacienda Real, como en 1805 
durante los años de 1810, cuando el cuerpo capitular cubrió gastos correspondientes al Estado central, por ejemplo la imposición extraordinaria sobre el pan y la carne en la ciudad que se extendió entre 1815 y 1819. Gravamen que explica el incremento de la carga impositiva ejercida por el Cabildo durante ese lapso, pero cuya recaudación se destinaba a gastos del gobierno central (Ensinck, 1990, p. 435). ${ }^{16}$

Uno de los principales ingresos con los que contaba la caja municipal eran, como vimos, los correspondientes al "derecho de corrales". En la gráfica 2 se presenta el itinerario descrito por la recaudación de este impuesto entre 1780 y 1820 . Puede distinguirse una tendencia suavizada al alza de lo recaudado entre el inicio del periodo y 1802, años durante los cuales el valor de ingresos por este ramo rondó sumas cercanas a los 2000 pesos. A partir de noviembre de 1803, el arancel de medio real por cabeza de ganado aumentó hasta llegar a los dos reales por animal, lo que explica el salto en la recaudación a partir de $1804 .{ }^{17}$

La caída abrupta de lo recabado durante 1810 se vinculó a los cambios de autoridades y administradores, cuando el tesorero de propios, Sebastián Eyzaga, que ejerció el cargo desde 1785, fue depuesto y reemplazado por Francisco Perdriel. ${ }^{18}$ La turbulencia de los cambios no sólo afectó al derecho de corrales, puesto que también mermó la recaudación total y especialmente el "nuevo impuesto", que cayó de 91000 pesos en 1809 a poco más de 17000 pesos.

En la gráfica 3 se presentan las recaudaciones del derecho de corrales de abasto como porcentaje dentro del total ingresado en concepto de propios y arbitrios (para el año 1788 no contamos con datos). Entre 1780 y 1798 este gravamen rondó entre 30 y $40 \%$ del total, con un pico superior a $40 \%$ en 1795 . Antes que a un incremento nominal significativo, el importante aumento porcentual de ese año se explica mejor por una caída de la recaudación total. Entre 1796 y 1801, su participación sobre la masa de propios decayó, con motivo esta vez de la recuperación de la recaudación.

La tendencia a la baja porcentual se interrumpió en 1802, y se revirtió notoriamente en 1804, dado que, como señalamos, el arancel se elevó a dos reales por cabeza de ganado introducida. Fue este aumento lo que produjo que el derecho de corrales trepara abruptamente desde algo más de

(20000 pesos) y 1807 (50 000) para socorrer a los labradores y para gastos de guerra, respectivamente (Ensinck, 1990, pp. 365 y 375).

${ }^{16}$ Debido a estas crecientes salidas, el Cabildo no sólo incrementó su peso fiscal sobre la población, sino que tomó préstamos y recibió donativos especialmente desde 1806 en adelante.

17 "Desde el 24 de noviembre de 1803 se fijó en 1늘 reales por cada novillo que se ha entablado, más medio real que antes se pagaba" (Ensinck, 1990, p. 358).

18 "Es removido perpetuamente de su empleo D. Sebastián Eyzaga, y que jamás pueda obtener confianza alguna, ni cargo subalterno en este Cabildo, ni aun pisar en las Casas Consistoriales" (Ensinck, 1990, p. 404). 


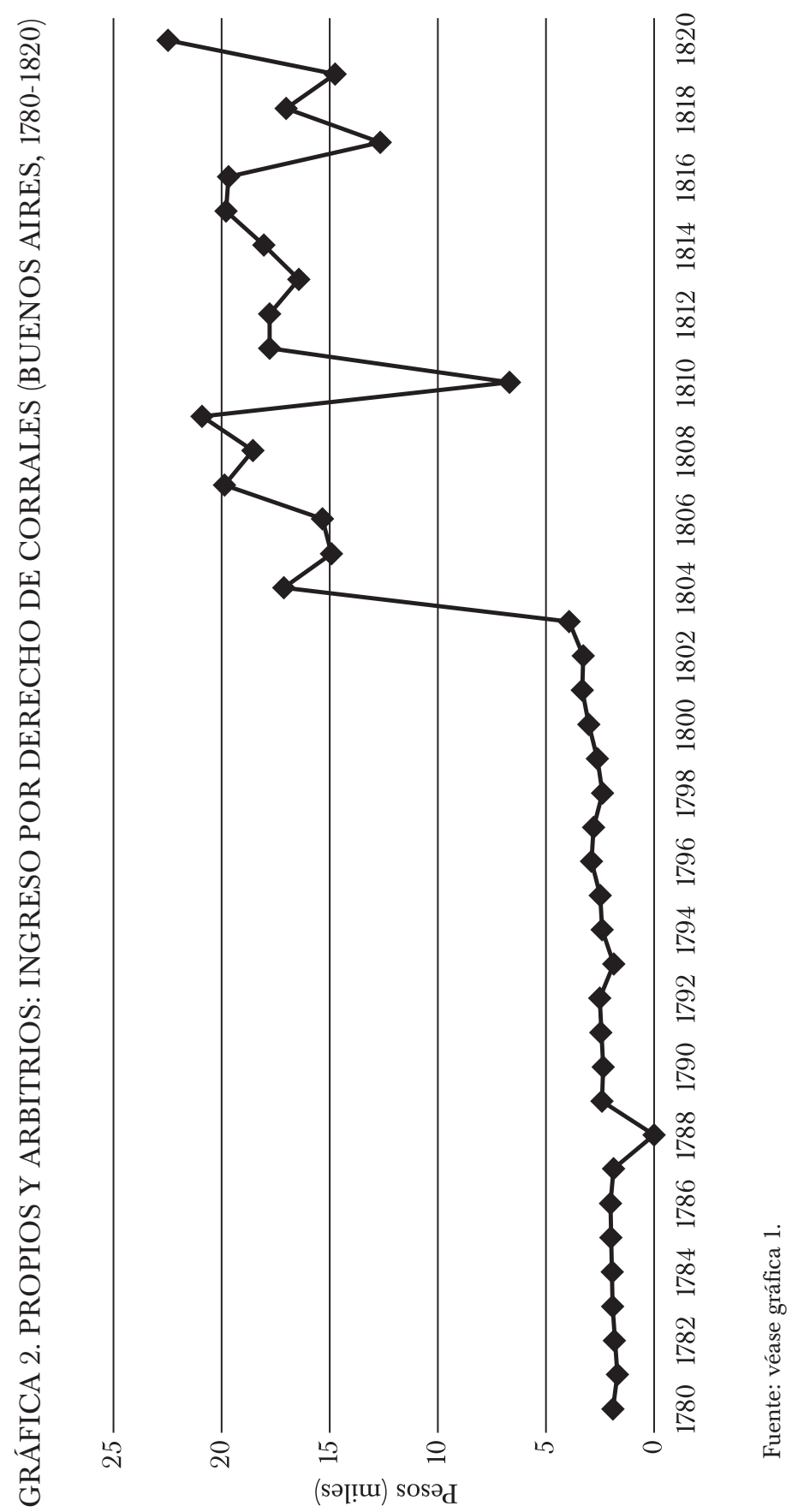




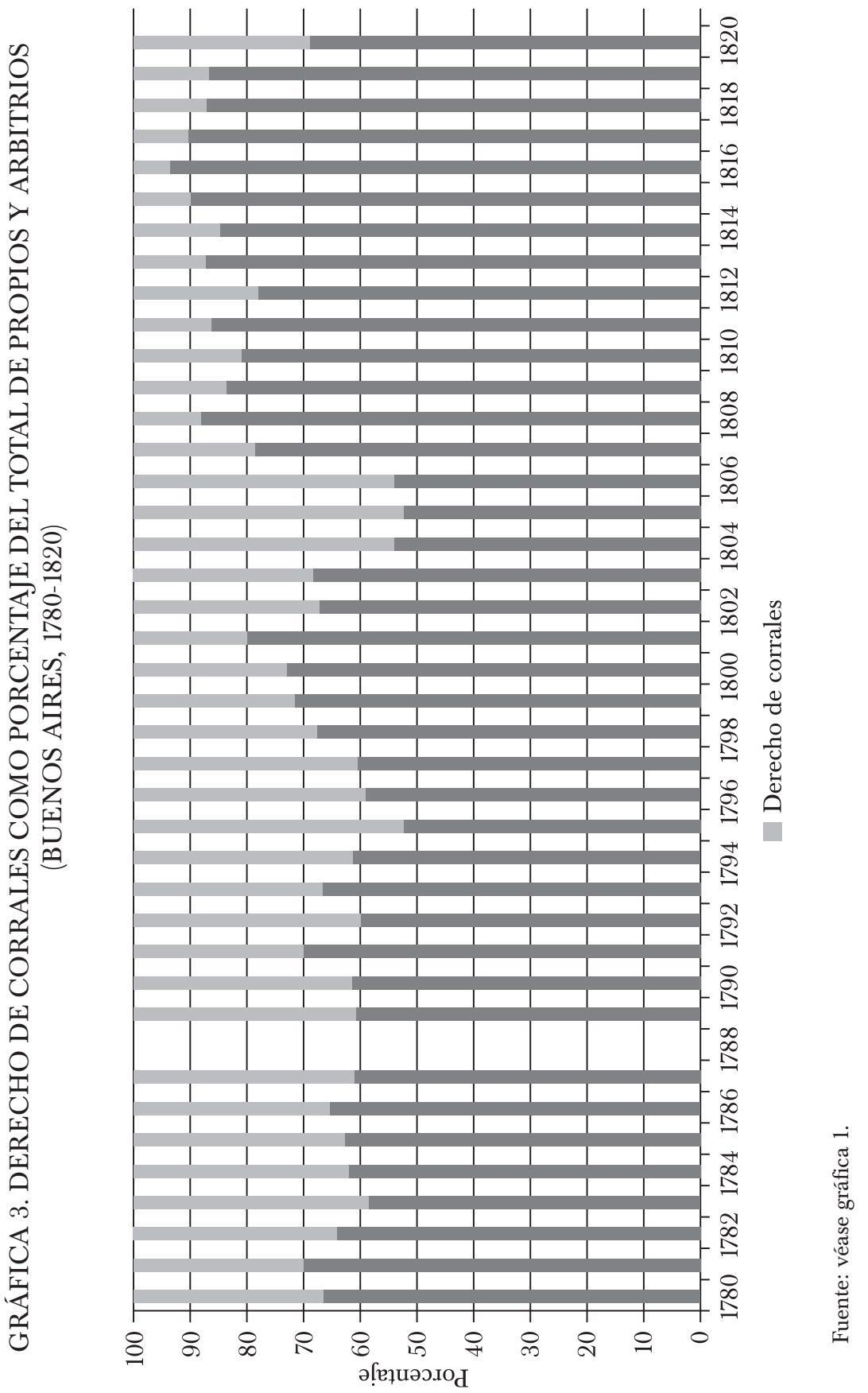


$30 \%$ sobre el total de ingresos capitulares en 1802-1803, hasta casi alcanzar $50 \%$ en 1806. Luego de esta fecha, la implementación del "nuevo impuesto" volvió a reducir la relevancia del de corrales hasta situarlo entre un 10 y $20 \%$ hasta 1815, cuando volvió a retroceder debido a la implementación del mencionado arancel extraordinario sobre el pan y la carne hasta 1819.

La importancia de este gravamen quedó graficada no sólo en los números y su continuidad durante las cuatro décadas sino también en los debates que llevaron adelante los capitulares durante el periodo. La necesidad de aumentar los propios y arbitrios fue una constante, tal como lo expresaba en 1785 el alcalde de primer voto "se hasia presiso con la maior brevedad el tratar de proponer nuevos arbitrios con que Subvenir a las atenciones de este M. I. C. por que siendo constante que a falta de ellos carecen de gratificaciones muchos individuos que le sirven, y no hay el numero de los que se necesitan en una Ciudad como esta Capital del Virreynato". 19

En dicho año se encargó entonces a los regidores Ramos Mexía y Santa Coloma que confeccionaran un presupuesto que permitiese identificar la cantidad de gastos en los que incurría el Cabildo y las posibles fuentes de recursos para aumentar sus fondos. ${ }^{20} \mathrm{El}$ presupuesto fue presentado ante las autoridades en 1786, y preveía aumentar tributos sobre establecimientos de diversión pública tales como casas de comedia, trucos, gallos, entre otras, así como gravar el comercio de algunos artículos como azúcares y aguardiente, amén de establecer contribuciones para las lanchas que comerciaban por el río Paraná (Ensinck, 1990, p. 235).

Sin embargo, la expansión fiscal que representaban estos nuevos gravámenes no resultó satisfactoria, por lo cual se gestionaron nuevas medidas ante el virrey para aumentar los propios, lo que cristalizó finalmente en el aumento de uno y medio real sobre el ganado introducido en los mercados. ${ }^{21}$ Aunque originalmente la suba del arancel se proyectaba destinarla a gastos específicos de la ciudad, ${ }^{22}$ la premura fiscal ,una vez más, determinó que se utilizaran para gastos corrientes.

Tan importante resultaron estos ingresos para el cuerpo municipal que el pedido que Antonio Obligado elevó en 1805 a los capitulares requirien-

19 Acuerdo del 11 de octubre de 1785. Libro XLVII, p. 594, f. 78, AECBA.

${ }^{20}$ Acuerdo del 20 de octubre de 1785. Libro XLVII, p. 598, f. 82, AECBA.

${ }^{21}$ También en Nueva España fueron comunes los pedidos de aumento de aranceles municipales para solventar gastos de policía urbana gestionados ante el virrey. Así lo demuestra Celaya (2014) para Veracruz, "era importante que el cabildo solicitante explicara el tipo de arbitrio, los bienes gravados, los contribuyentes y el destino de los recursos” (p. 44).

22 Especialmente para la formación de un pósito de trigo, que finalmente no se construyó. Sobre este tema, véase Garavaglia (1991, pp. 20 y ss). 
do eliminar el nuevo arancel fue rotundamente denegado, no sin antes cuestionar los intereses e integridad del solicitante:

Se leió un pedimento o representación que ha hecho a la Superioridad don Antonio Obligado, en que suponiéndose apoderado de los hacendados pide se levante la contribución que se ha impuesto a los reseros de real y medio por cabeza de ganado que matan, y que este I. C. rinda cuenta de lo que por esta razón ha percibido hasta la fecha; cuia representación ha pasado a informe el Excelentisimo Señor Virrey. Y los SS. considerando y advirtiendo que ella es mas bien un líbelo infamatorio contra el Cuerpo, producido por un sugeto a quien no se tiene por parte en semejante negocio acordaron que el Señor alcalde de primero voto consulte el punto sobre lo que deberá hacerse en el particular. ${ }^{23}$

\section{EL DERECHO DE CORRALES EN RIESGO: ABASTO E INTRODUCCIONES CLANDESTINAS EN LA CIUDAD}

En las discusiones que mantenían los miembros del Cabildo, los problemas que presentaba la recaudación del impuesto de corrales fueron tomando relevancia. La preocupación de los regidores se centraba en las faenas que se realizaban por fuera del control de los administradores de corrales, lo que posibilitaba evitar el pago de los impuestos correspondientes.

Estas faenas aparecían asociadas al robo y contrabando de ganado, y habían llevado a la implementación de corrales de abasto en la ciudad en 1775 , con el doble objetivo de alimentar los propios de la ciudad y de controlar la propiedad de los novillos introducidos para el consumo de carne porteño:

En el año de mil setecientos setenta y sinco [...] que se estableciesen por cuenta del Cabildo los corrales para encerrar ganado para el abasto de la ciudad, prohibiéndoles a los diferentes particulares que los obtenían, llevando medio real por cabeza para que de este modo se pudiese más fácilmente celar, assi el robo de los ganados, como la matanza de bacas, todo lo que fue aprobado por el Exmo. Sor. Don Juan José de Vértiz (Documentos, 1914, p. 147). ${ }^{24}$

En 1783, el fiel ejecutor señalaba la continuidad de la comercialización de ganado ajeno, dejando entrever la poca eficacia de los bandos y

${ }^{23}$ Acuerdo del 29 de noviembre de 1805. Libro LX, f. 104, p. 172, AECBA.

${ }^{24}$ Acuerdo del 21 de enero de 1795, AECBA. Hasta mediados del siglo XVIII el mercado de la carne había funcionado mediante el estanco (monopolio). Sobre el tema del estanco en la primera mitad del XVIII puede consultarse Dupuy (2010). 
reglamentaciones: ${ }^{25}$ "los Azendados venden y matan, no sólo los Toros y Novillos desu Marca, sino los agenos y agenas, todo lo qual es contra la causa pública" (Documentos, 1914, p. 169).

En 1803, desde el Ayuntamiento se señalaba la especial responsabilidad de los administradores de los corrales en asegurar el pago de los derechos, así como de evitar las faenas de animales de dudosa procedencia:

será de la obligación de los administradores zelar que no se hagan matanzas de ganado fuera de los corrales, que no se introduzca el que no sea de competente edad, y si se introdugere, dé cuenta antes de matarlo al Señor Fiel Executor, y por último que se venda su carne para el consumo público, a fin de evitar por este medio los robos de la campaña, los fraudes que pueden hacerse a los consumidores, y también para que se cobren debidamente las expresadas contribuciones que interesan al bien público[...]. ${ }^{26}$

Era en los alrededores de la ciudad donde, según los capitulares, se faenaban animales -de dudosa propiedad- para evitar su introducción en los corrales y el pago del arancel. Así lo señalaban los capitulares en 1804: "previene a V.S. $\mathrm{q}^{\mathrm{e}}$ se halla ympuesto de $\mathrm{q}^{\mathrm{e}}$ varios sujetos se han dedicado a matar reses en las ynmediacion ${ }^{\mathrm{s}}$ de esta ciudad distantes de los corrales por no pagar derecho alguno traen la carne a vender al pueblo (Documentos, 1914, p. 169).

Pero también en los propios corrales las cabezas ingresadas podían eludir los controles. En ese mismo año de 1804, el Cabildo encomendó a un comisionado la supervisión de los tres corrales de abasto existentes en la ciudad (Santo Domingo, Recoleta y Carricaburu). Al cabo de unos días, el registro del comisionado arrojó como resultado un número importante de introducciones que evitaban el pago del arancel: en Santo Domingo se declararon 421 novillos sobre un total de 487 cabezas ingresadas; en Recoleta 477 sobre 765, y en Carricaburu 237 sobre 251. Asimismo, en el informe también se señalaba que en las quintas de alrededores se realizaban matanzas de ganado para vender su carne en la ciudad. ${ }^{27}$

${ }^{25}$ Bando del virrey Juan José de Vértiz del 9 de junio de 1779 "prohibiendo la extracción de sebo y grasa, a fin de priorizar el abasto urbano"; Bando del 9 de marzo de 1791 "Prohíbe matanzas perjudiciales y faenas clandestinas de cueros, así como las extracciones ilegales de ganado y cueros al Brasil y a otros dominios portugueses"; Bando del 12 de septiembre de 1791 "dictando reglas para impedir los robos de animales y de cueros, y otros desórdenes"; Bando del 5 de marzo de 1792 "reglamentando la compra y venta de cueros. Castiga además el contrabando y la matanza de reses robadas". Todos en Sala IX, Bandos y disposiciones reales y virreinales, AGN.

${ }^{26}$ Acuerdo del 14 de diciembre de 1803. Libro LIX, f. 66v, p. 328, AECBA.

${ }^{27}$ Todos estos datos en "Expediente en el cual se hacen constar las defraudaciones que se cometían al erario público en la matanza de los corrales de abasto, julio y agosto 1804" (Documentos, 1914, p. 169). 
Las medidas a implementar para remediar estas prácticas se discutieron con frecuencia en el Ayuntamiento, ${ }^{28}$ lo que indica su continuidad como un problema al que evidentemente resultaba difícil encontrar solución:

que en todos los tiempos se han conocido los considerables perjuicios y fatales consecuencias que resultan de la libertad y franquess en introducir ganados de marcas no conocidas, pero estas consideraciones, y repetidos reclamos de los mismos hacendados o criadores, ha mirado siempre este M. I. A. como asunto de su primera atención, zelar efiscasmente esta introducción que rara vez deja de ser fraudulenta y maliciosa (cursivas mías). ${ }^{29}$

La creación de nuevos corrales de abasto fue una de las medidas que el Cabildo ensayó para paliar las faenas clandestinas y el robo de ganado, tal como ocurrió en Flores, situado en inmediaciones de la ciudad, cuando en septiembre de 1810 se encomendó la confección de un presupuesto para erigir un corral que comenzaría a funcionar durante esa década. ${ }^{30}$ Sin embargo, en 1814 Manuel José Galup, el entonces fiel ejecutor, resaltó una vez más la existencia de prácticas clandestinas y el inconveniente que suponían en relación al respeto por la propiedad. Tal como se había denunciado diez años antes, se continuaban sacrificando animales en el ámbito periurbano para luego comercializarlos en el mercado, evitando el pago de impuestos: "hace presente [el fiel ejecutor] el abuso introducido de hacer matanzas clandestinas en varios corrales situados extramuros de la ciudad de ganados, que debían entrar y matarse en los de este ayuntamiento, asi para que no fuese perjudicado el cobro del derecho que adeuda por caveza, como para evitar por dho. medio los robos, o se mate ganado mal habido" (cursivas mías). ${ }^{31}$

El robo y la comercialización de ganado ajeno eran prácticas que aparecían asociadas a las introducciones clandestinas, las cuales perjudicaban seriamente uno de los ingresos más significativos de los propios del cabildo

${ }^{28}$ A las referencias de 1775 y 1795 pueden sumarse los pedidos del fiel ejecutor en 1782 en un informe dirigido al gobernador, donde señalaba la "necesidad urgentissima de remediar el abuso yntroducido en la campaña en hacer matanzas sin reparar en lo ageno" (Documentos, 1914, pp. 38-39) y Acuerdo del 13 de diciembre de 1782, AECBA. Cuestiones similares abordó el propio fiel ejecutor el 24 de mayo de 1783 (Documentos, 1914, pp. 39-46).

${ }^{29}$ Acuerdo del 23 de mayo de 1808, AECBA.

30 "Hizo presente el señor regidor fiel egecutor haverle significado el alcalde de la hermandad que con motivo de no haver corral en San José de Flores para matanza de ganado, se hacen en aquel lugar infinitos robos de esta especie, los cuales podrán desde luego evitarse con que en aquel lugar se haga un corral para el indicado efecto". Acuerdo de septiembre 1810, f. 5, p. 245 , AECBA.

${ }^{31}$ Acuerdo del 26 de abril de 1814, AECBA. 
como lo era el derecho de corrales. Quienes buscaban evadir el pago de aranceles solían desarrollar la matanza y desposte de ganado en las inmediaciones de la ciudad, para luego introducir la carne en los mercados, aunque también la evasión podía ocurrir en los propios corrales citadinos si se lograba escapar a los controles establecidos por el fiel ejecutor. Lejos de agotarse en el momento de la introducción del ganado, las prácticas ilegales atravesaban todo el proceso productivo, hundiendo sus raíces en la campaña.

\section{CORRALES EN EL HINTERLAND PORTEÑO Y PREOCUPACIÓN POR LA ESCASEZ DE CARNE}

La asociación de intereses entre Ayuntamiento y hacendados de la campaña por evitar el robo de animales, incrementar la recaudación fiscal y asegurar el abastecimiento de carne llevó a la creación de corrales de abasto no sólo en inmediaciones de la ciudad sino también en los diferentes partidos rurales de la jurisdicción porteña. Así lo expresaba en 1783 el fiel ejecutor Gregorio Ramos Mejía, al presentar un informe sobre la necesidad de controlar el desorden en la matanza de ganados: "El establecimiento de corrales en la costa de San Isidro, Conchas y Cañada de Morón, pedidos por el dho Apoderado y que V. $S^{a}$ acordó en el año pasado de ochenta y dos, es otro alivio para los robos que suelen hacer a los Hacendados, y ael mismo Tmpo. otro medio que evite la matanza de Bacas y V. S. ${ }^{a}$ aumente sus cortísimos Propios" (cursivas mías). ${ }^{32}$

Esta convergencia de la preocupación de los ganaderos con el erario quedó reflejada en 1794 cuando el gremio de hacendados elevó a las autoridades virreinales un pedido para controlar los robos que se sucedían en el hinterland y que causaban perjuicios a la Real Hacienda:

ni los haz. ${ }^{\text {dos }}$ y labradores pueden consultar seguridad alguna, ni tomar increm. ${ }^{\text {to }}$ las crías de los gan. ${ }^{\text {dos }}$ y demas haz. ${ }^{\text {das }}$ de campo, aniquiladas con los desordenes $\mathrm{q}^{\mathrm{e}}$ se sufren en perjuicios gravisimos de la Provincia, del Público, del Estado, del Comerz ${ }^{\circ}$, de la $R^{l} H a z^{d a}$, y la monarquía toda; pues $q^{\mathrm{e}}$ motivando estas malas gentes la privaz. ${ }^{\text {on }}$ de fomentarse las produz. ${ }^{\text {nes }}$ de más fértiles campañas, a todos abraza el mal (cursivas mías). ${ }^{33}$

${ }^{32}$ Véase "Representación del fiel ejecutor al I. C. para que se atage el desorden en la matanza de Ganado y se sustituya en parte el abasto de carne de novillo por la de carnero" (2 de mayo de 1783) (Documentos, 1914, p. 49). El resaltado es mío. Sobre el pedido del apoderado de los hacendados, véase Sesión del 5 de diciembre de 1782. Libro XLIV, p. 119, AECBA.

${ }^{33}$ Obrado a representación de los Apoderados del Gremio de Hazendados sobre robos de ganados y otros excesos en las campañas. Cuerpo XIII, 2-6-45, 1794, f. 2v. Archivo Histórico de la Provincia de Buenos Aires (en adelante AHPBA). 
Durante los años analizados, fueron recurrentes las medidas y apresamientos de individuos que ejercían prácticas clandestinas en la campaña como el abigeato, la comercialización sin licencias y el robo de ganado y cueros, lo que evidencia lo extendida que se hallaba dicha problemática. ${ }^{34}$ En 1808, Juan Lorenzo Castro, alcalde del partido rural de Chascomús, planteó al Cabildo un conjunto de problemas que atravesaba la producción ganadera destinada al abasto de carne de la ciudad. En su presentación, se abordaban algunas de las dificultades vinculadas al respeto de la propiedad del ganado que se remitía desde la campaña. El alcalde expuso la falta de control existente (pese a las repetidas normativas) en el tránsito de los animales por los diferentes partidos y en las posibilidades de arreo de ganado ajeno: "los conductores en los ganados para el abasto de esta Capital transitan por aquellos territorios libremen. ${ }^{\text {te }} \mathrm{y}$ sin examen de los ganados q. ${ }^{e}$ conducen, por cuio motivo mesclan ganados agenos o robados, y este es desorden q $q^{e}$ produce los daños q están a la vista" (cursivas mías) (Documentos, 1914, p. 192).

Señalaba a la proliferación de "vagos" como una de las causas principales de la extensión de los robos:

Que estando llenas aquellas Campañas de Vagos y otros individuos q a la sombra de tener una manada de Yeguas y diez o doze cavallos con marca ya se computan como hacendados [...] los pocos animales que tienen pastan en terrenos agenos y no tienen modo de substentarse no haciendo matanza de ganados agenos: conviene e importa $q^{e}$ se extingan y aprehendan estas clases de hacendados [...] sucediendo lo mismo con los muchos agregados $q^{e}$ tienen estos ultimos porq todos ellos se mantienen de ganados agenos (cursivas mías) (Documentos, 1914, pp. 193 y ss.).

Infructuosamente, Castro propuso una serie de medidas a implementar con el fin de evitar los males señalados. Entre sus propuestas trató de impulsar un mayor control sobre el ganado circulante a través de la supervisión de los alcaldes de hermandad, a quienes proponía otorgarles la potestad de exigir licencias expedidas por el fiel ejecutor para conducir animales hacia la ciudad. También propuso la necesidad de contar con comprobantes de compra, acreditados por "ganaderos o criadores":

en su concepto se podrán evitar [los problemas señalados] seguram. ${ }^{\text {te }}$ ordenándose por punto gral y publicandose alli, $\mathrm{q}^{\mathrm{e}}$ todos los $\mathrm{q}^{\mathrm{e}}$ lleven lisencias del Fiel Executor $\mathrm{p}^{\mathrm{a}}$ comprar y conducr ganados $\mathrm{p}^{\mathrm{a}}$ el consumo, se presenten con ellas al Alcalde

${ }^{34}$ Por mencionar un dato, sólo en la sección Juzgado del Crimen del AHPBA existen registrados, entre 1780 y 1820 unas 30 causas por abigeato, 54 por cuatrerismo y más de 200 por robo, sólo para la campaña de Buenos Aires. 


\begin{abstract}
$\mathrm{p}^{\mathrm{a}} \mathrm{q}^{\mathrm{e}}$ tome razón, y $\mathrm{q}^{\mathrm{e}}$ cuando se restituian executen lo mismo y presenten los certificados competentes de los ganaderos o criadores $\mathrm{q}^{\mathrm{e}}$ acrediten las cavezas de ganados $\mathrm{q}^{\mathrm{e}}$ conduzcan [...] imponiendo a los conductores la pena competente por su contravención, y si huviese fraude, como el arresto de sus personas y perdida de todos los ganados (Documentos, 1914, pp. 193 y ss.).
\end{abstract}

La respuesta del fiel ejecutor a los reclamos de Castro en 1808, dejando en suspenso las medidas solicitadas, marcó la tensión existente entre las posibilidades de implementar un control más eficaz sobre la propiedad de los animales y la capacidad de atender al consumo de carne en la ciudad:

Los males querepresenta el nuevo Alc. ${ }^{\circ}$ de Hermandad en su $1^{\circ}$ Capítulo son ciertos, y exigen toda atension $\mathrm{p}^{\mathrm{a}}$ su remedio, pero como este tiene sus trabas e incombenientes enla execucion, y su trascendencia puede perjudicar el havasto público $q$ debe consultarse con preferencia a todo, contemplo por lo mismos hay necesidad de otra meditación $\mathrm{q}^{\mathrm{e}}$ fundada en conocimientos mas inmediatos dela materia, corte el mal en su origen (cursivas mías) (Informe del fiel ejecutor Esteban Romero, 25 de enero de 1808. Documentos, 1914, p. 195).

Las palabras de Esteban Romero evidencian que uno de los obstáculos con el que chocaba el cuerpo capitular a la hora de ejecutar mayores controles sobre el ganado y las faenas clandestinas era el problema de garantizar el abasto de carne. Así lo dejan entrever sucesivas declaraciones de las autoridades a lo largo de todo el periodo, subrayando lo imperioso de nutrir de entradas regulares de animales al mercado de carne citadino.

En enero de 1780, el virrey Vértiz se refirió a este problema al momento de establecer el bando que dividía la campaña en secciones para ordenar el abastecimiento de carne a la ciudad, señalando el riesgo de conflictividad social que conllevaba la caída del suministro: "Que en estos mismos terminos salgan las demas Partidas cada una al Partido de su destino de modo que quando se halle abastecida la Ciu. ${ }^{\mathrm{d}}$ con Reses del primero partido, dos o tres días ya antes que se experimente el clamor del Pueblo esté proveida con las del Segundo, y así hasta el último" (cursivas mías) (Documentos, 1914, p. 18). ${ }^{35}$

En 1787, la urgencia por abastecer de novillos al mercado urbano llevó al fiel ejecutor a autorizar a los reseros para que introdujeran animales "orejanos" (es decir, sin marca de propiedad) tomados en la frontera, lo

${ }^{35}$ En Buenos Aires no tuvieron lugar motines por escasez o precios altos; por ello evitar el clamor, en palabras de las autoridades, parece vincularse a mantener una tradición de paz social y desarticular situaciones de malestar popular y quejas antes de su cristalización en motines. Tampoco pueden descartarse referencias a experiencias de otras ciudades, aunque no hemos encontrado alusiones explícitas. 
que evidenciaba que el imperio de la necesidad de consumo de carne se imponía por sobre el control de la propiedad. ${ }^{36}$

El temor a la escasez se presentó también durante 1791, en ocasión de que el gremio de hacendados contribuyese con el dinero comprometido con el Cabildo para el recibimiento del virrey. A fin de recuperar la suma pautada en unos 10000 pesos, se estableció que los productores debían contribuir con medio real por cabeza introducida al mercado. Sin embargo, ante la negativa de los hacendados de afrontar este gravamen y el riesgo de escasez en la entrada de vacunos, los introductores terminaron desembolsando la suma, pero trasladando el impuesto al precio de la carne, lo cual se intentaba evitar a toda costa. Esta peligrosa situación fue graficada por el fiel ejecutor ante los cabildantes

que haviendoselo querido descontar [el 1/2 real a los hacendados] el introductor de su Ganado a prorrata conforme a los citados oficios de V. E. de ningún modo lo han consentido, resistiéndose expresam. ${ }^{\text {te }}$ a ello [...] Los introductores, por no exponer a la ciudad a repetidas escaseces a que a ellos se les formase algún cargo, se vieron precisados a pagarles a los Hacendados el precio íntegro y contribuir con el citado medio real por cabeza: ha resultado que esta contribución que V. E. llama nuebo impuesto la ha satisfecho el publico de esta Ciudad, y no los hacendados porque haviendola pagado los introductores de las reses la han cobrado de los consumidores, vendiéndoles la carne mas cara de lo que antes acostumbraban, por no tener sobre si esta gavela (cursivas mías). ${ }^{37}$

La principal preocupación capitular giraba en torno a cubrir las necesidades de carne. En 1804, el regidor Gregorio Ramos Mexía -antiguo fiel ejecutor- alertaba en su Memorial sobre el Abasto el riesgo que implicaba la ausencia de abastecedores de carne en los mercados: "¿de quiénes se valdrá el Cabildo para proveer a la Ciudad en un ramo, cuia falta de un solo día expone a un tumulto?" (cursivas mías). ${ }^{38}$

\footnotetext{
${ }^{36}$ Debido a la sequía, gran parte del ganado había huido hacia zonas de frontera en busca de agua y pasturas. Este diagnóstico y la autorización para ingresar estos animales en los mercados citadinos, véase Acuerdo del 2 de octubre de 1787. Libro XLVII, f. 205, pp. 387-388, AECBA. En 1782 se había prohibido tomar ganado de la frontera con los indígenas, debido a los "excesos cometidos por los Ganaderos que salen a la campaña para abastezer esta ciudad insultando a los Indios Infieles", lo que confirma que la autorización de 1787 era una medida no deseada y de excepción. Véase Consulta del Teniente de Rey Diego de Salas al Cabildo, 18 de septiembre de 1782 (Documentos, 1914, p. 23).

${ }^{37}$ Acuerdo del 31 de diciembre de 1791. Libro LII, ff. 94 v. y 95, p. 693, АЕCBA.

${ }^{38}$ Libro LIX, f. 182 v, p. 470, AECBA. También en 1803 el síndico procurador subrayaba la importancia del abasto de carnes: "el numeroso vecindario de esta Ciudad necesita asegurar con la maior solidez y formalidades posibles la carne para su abasto, que es el renglón más principal”. Acuerdo del 31 de octubre de 1803. Libro LIX, f. 41v, p. 298, AECBA.
} 
En una misma línea se expresó, en 1808, el administrador de los corrales de Santo Domingo, Lorenzo López. Sus palabras confirman, por un lado, el origen dudoso de muchos de los animales que cotidianamente se ingresaban a los mercados. Por otro, que el riesgo de endurecer los controles podía dar lugar a una crisis por escasez de alimentos

la imposibilidad moral q ofrece el examen e indagación de las certificaciones que generalmente vienen firmadas a ruego de los verdaderos dueños, por personas desconocidas; y a veces aceleradas las ventas por quienes alegan facultad, pero que no la han acreditado; en cuyos casos no es fácil evitar el fraude $q^{\mathrm{e}}$ bajo estos títulos, diariamente se comete, y mayormente quando de tomarse alguna providencia seria, podría sentirlo el publico por las escaseses continuas que ocurrirían, siendo tan general y frequente esta conducta en los Receros (cursivas mías) (Documentos, 1914, p. 197).

En pos de esta preocupación y del afán de regular el peso de la carne y el pan al momento de su venta, durante todo el periodo abordado se emitieron recurrentes disposiciones para el control de pesos y medidas. En 1813 , en uno de los debates desplegados sobre si era más conveniente vender estos artículos de primera necesidad por peso o por medida, también se aludía al riesgo de tumultos:

Y haviendose entrado a nuevas discusiones con la proligidad que requiere la materia, y en que se halla fuertemente empeñado este Ayuntamiento, para acallar el clamor del Pueblo, se tocaron graves inconvenientes en unas, y otras propuestas, que las hacen desde /luego inadmisibles por su discrepancia y porque con ellas no se ataca el mal en su origen, pues siempre queda a arvitrio de los vendedores continuar el abuso con que hasta aquí han procedido, vendase la carne por peso o por precio en sus respectivas partes, a mas de que no acordando los abastecedores de los tres corrales en un solo modo de vender la carne al público, presenta esto un desorden quizá mayor que el mal que se piensa evitar (cursivas mías). ${ }^{39}$

Finalmente, cabe señalar también que en 1817 y 1818 la demanda de ganado para los saladeros se mostró por primera vez factible de poner en serio riesgo el abasto urbano y alentó la suba de precios de la carne. La respuesta del Cabildo volvió a entroncarse en la línea de priorizar el abasto citadino, buscando establecer acuerdos entre saladeristas, abastecedores y ganaderos a fin de evitar el desabastecimiento. ${ }^{40}$

Se conjugaban entonces dos necesidades para el cuerpo capitular: evitar la carestía de carne (y los potenciales tumultos) y aumentar sus dema-

${ }^{39}$ Acuerdo de julio de 1813, foja 152 v, p. 622, AECBA.

${ }^{40}$ Para una descripción del conflicto véase Garavaglia (1999, p. 229) y Sala IX 19-6-11, AGN. 
crados ingresos fiscales. La tolerancia con la introducción de ganado ajeno y/o con marcas adulteradas se explica gracias a que, si bien eran prácticas nocivas, a entender de las autoridades resultaban un mal menor. Dada la importancia del derecho de corrales para el presupuesto del Cabildo y que, aun en casos de animales de propiedad dudosa, los reseros podían abonar los aranceles correspondientes, se lograba así engrosar los escuálidos recursos fiscales del cuerpo capitular y se evitaba la tan temida escasez de alimentos en la ciudad.

\section{CONCLUSIONES}

En primer lugar, cabe destacar que fue posible identificar algunos aspectos de la compleja vinculación entre Real Hacienda y fiscalidad capitular. Constatamos que las pautas que intentó imponer la Junta Superior a través del reglamento de 1795 no se cumplieron en la práctica. Gracias a las posibilidades que presentaban los gastos de cuarta clase o extraordinarios, se incluyeron erogaciones que en teoría no corrían a cargo del Cabildo (como los gastos militares) lo cual si bien presionó sobre sus fondos, también justificó y permitió que este extendiera sus atribuciones fiscales captando nuevos gravámenes. Entonces, lejos de aparecer como un municipio controlado a fines de la colonia, el itinerario seguido por el Ayuntamiento porteño parece asemejarse más a los perfiles de sus pares de Nueva España, que presentaron mayores márgenes de autonomía en el marco del avance del reformismo borbón.

El aumento del volumen impositivo (creación de nuevos impuestos, aumento del derecho de corrales) se tradujo en una mayor carga fiscal sobre la población, que como vimos tuvo lugar especialmente entre 1807 y 1816, para desacelerarse luego. Así, se pasó de una presión fiscal de dos reales per cápita a fines del siglo XVIII, hasta alcanzar picos de hasta seis pesos por habitante de la ciudad en 1816. De esta manera, el Cabildo no sólo pudo afrontar los ingentes gastos de guerra del periodo sino que pasó de ser receptor de fondos de la Real Hacienda a fines del siglo XVIII -especialmente del impuesto municipal de guerra- a efectuar suplementos a la misma en momentos de urgencia, tal como ocurrió en 1807 y 1808. Algo similar ocurrió en la década de 1810, cuando el Ayuntamiento porteño recabó fondos destinados a gastos del gobierno central de las Provincias Unidas.

Por otra parte, el repaso por las recaudaciones del derecho de corrales permitió apreciar que era un impuesto central dentro de los propios y arbitrios de Buenos Aires. Con altibajos, su recaudación representó porcentajes importantes de los recursos con los que contaba el Cabildo, pues 
mostraba una tendencia al crecimiento especialmente hacia el final de la colonia, tanto en términos absolutos como relativos, morigerados estos últimos por la creación del nuevo impuesto hacia 1806. Si bien centrales dentro de un universo de ingresos siempre limitado, su recaudación encontró escollos en la práctica. El examen realizado sobre las discusiones entabladas por los capitulares a lo largo de cuatro décadas evidenció que uno de los problemas centrales que la recepción impositiva encontraba era la existencia de prácticas ilegales, tanto en la producción ganadera como en la introducción de animales en el mercado urbano.

Como creemos haber comprobado, la recaudación del derecho de corrales se vio sometida a una contradicción: si por un lado el mayor control sobre el ganado podía arrojar mejores rendimientos fiscales, por el otro, el endurecimiento de la vigilancia podía generar una caída en el volumen de animales ingresados al mercado, aumentando las posibilidades de tumultos por carestía y poniendo en riesgo la recaudación. Este virtual escenario fue tenido muy en cuenta por los regidores, quienes priorizaron mantener un flujo constante de vacunos hacia el mercado citadino antes que implementar controles más estrictos sobre la propiedad del ganado en pie. Aun en los casos de origen dudoso, los reseros podían abonar el impuesto correspondiente por su introducción, lo cual alimentó la tolerancia hacia las prácticas ilegales.

La conflictividad apareció así condicionando el accionar gubernamental y las políticas fiscales municipales, tomando la forma de una potencial extensión del clamor del pueblo que se cernía como una amenaza a la gobernabilidad, plausible de materializarse ante la escasez de carne. Desde diferentes instancias -los administradores de los corrales, el virrey Vértiz, los capitulares- el despliegue de un accionar más riguroso en la sanción y erradicación de faenas ilegales fue considerado como un posible detonante de protestas por escasez. Por ello consideramos que el clamor se presentó, durante los años analizados, 1780-1820, como factor limitante del accionar gubernamental en un sentido que definimos como thompsoniano: ${ }^{41}$ no sólo influyendo en la regulación de los precios sino poniendo límites al accionar gubernamental.

${ }^{41}$ Respecto a cómo los conflictos sociales por escasez de alimentos limitaron la lógica de mercado, señalaba Thompson (1995, p. 271) "Si el mercado fue un campo de batalla de la guerra de clases en la misma medida en que llegaron a serlo la fábrica y la mina durante la revolución industrial, entonces la amenaza del motín afectaría a la situación total del mercado, no sólo en años de escasez, sino también en años de cosecha media, y no sólo en pueblos destacados por su susceptibilidad al motín, sino también en aldeas donde las autoridades deseaban preservar una tradición de paz. Por muy meticulosamente que cuantifiquemos los datos disponibles, éstos no pueden mostrarnos a qué nivel habrían subido los precios si se hubiera eliminado totalmente la amenaza del motín.” 


\section{LISTA DE REFERENCIAS}

Amaral, S. (2011). Las finanzas arcaicas: la atención del déficit fiscal en la Real Caja de Buenos Aires, 1789-1811. Revista Investigaciones y Ensayos, 60, 381-436.

Angulo, M. (2002). Los ingresos y gastos procedentes de las rentas provinciales, 17681784. Revista de Historia Económica, 20(3), 479-507. Recuperado de http://hdl.handle.net/10016/2204

BARRIERA, D. (2010). Justicias, jueces y culturas jurídicas en el siglo XIX rioplatense. Nuevo Mundo Mundos Nuevos. Recuperado de https://nuevomundo.revues.org/59252

Bertrand, M., Dubet, A.; Solbes, S. y Torres, R. (2014). Haciendas locales y haciendas estatales en las monarquías francesa y española: la construcción territorial del poder (siglo XVIII). Revista Tiempo, Espacio y Forma, 27, 15-35. DOI: 10.5944/ etfiv.27.2014.13700

Bustamante, C. (2010). Los propios y bienes de comunidad en la provincia de Tlaxcala durante la aplicación de las reformas borbónicas. Estudios de Historia Novohispana, 43, 145-182. Recuperado de http://www.revistas.unam.mx/index.php/ehn/ article/view/23473

Camarda, M. (2015). La región Río de la Plata y el comercio ultramarino durante las últimas décadas del siglo XVIII: actores, circulación comercial y mercancías (Tesis doctoral). Universidad Nacional de La Plata, Argentina. Recuperado de http://hdl.handle. net/10915/50827

Celaya, Y. (2014). Impuestos locales en Nueva España: negociación y obra pública en el Ayuntamiento de Veracruz en el siglo XVIII. Revista Tiempo, Espacio y Forma, 27, 37-59. DOI: 10.5944 /etfiv.27.2014.12708

Contsworth, J. (1990). Los orígenes del atraso. México: Alianza Editorial Mexicana.

Congost, R. (2011). De la idea de una propiedad absoluta a los derechos de propiedad como construcción social. Nuevos retos para los estudios históricos. Revista Estudios del ISHiR, 1(1), 71-81.

Cuesta, M. (2006). Evolución de la población y estructura ocupacional de Buenos Aires 1700-1810. Papeles de Población, 12(49), 205-238.

Cuesta, M. (2009). Impuestos imperiales: la Caja Real de Buenos Aires (1700-1800). Temas de Historia Argentina y Americana, 14, 27-56. Recuperado de http://bibliotecadigital.uca.edu.ar/repositorio/revistas/impuestos-imperiales-caja-real-buenosaires.pdf

Dedieu, J. P. (2014). El núcleo y el entorno. La Real Hacienda en el siglo XVIII. Revista Tiempo, Espacio y Forma, 27, 161-188. DOI: 10.5944/etfiv.27.2014.13705

Documentos para la historia argentina (1914). Tomo IV. Abastos de la ciudad y campaña de Buenos Aires (1773-1809). Buenos Aires: Compañía Sudamericana de Billetes.

Dubet, A. (2010). ¿'Tesorería Mayor o Tesorería General? El control contable en los años 1720: una historia conflictiva. De Computis, Revista Española de Historia de la Contabilidad, 13, 95-132. Recuperado de www.decomputis.org/dc/articulos_doctrinales/dubet13.pdf 
Dupuy, A. (2010). El estanco de la carne y su crisis en Buenos Aires colonial desde una visión comparativa. Revista Brasileira de História, 30(60), 211-231. DOI: 10.1590/ S0102-01882010000200012

Engerman, S. y Sokoloff, K. (1999). Dotaciones de factores, instituciones y vías de crecimiento diferentes entre las economías del Nuevo Mundo. Una visión de historiadores de economía estadounidenses. En S. HABER (comp.), Cómo se rezagó la América Latina: ensayos sobre las historias económicas de Brasil y México, 1800-1914 (pp. 305-358.). México: Fondo de Cultura Económica.

Ensinck, O. (1984). La Real Hacienda de Santa Fe. Rosario: Pontificia Universidad Católica Argentina.

Ensinck, O. (1990). Propios y arbitrios del Cabildo de Buenos Aires, 1580-1821: historia económica de una gran ciudad. Madrid: Instituto de Cooperación Iberoamericana.

Galarza, A. F. (2015). La fiscalidad en el Río de la Plata tardocolonial: un posible balance historiográfico a partir de las Cajas Reales. Bibliographica Americana. Revista Interdisciplinaria de Estudios Coloniales, 11, 9-30.

Garavaglia, J. C. (1987). El Río de la Plata en sus relaciones atlánticas: una balanza comercial (1779-1784). Economía, sociedad y regiones (pp. 65-117). Buenos Aires: Ediciones de la Flor.

Garavaglia, J. C. (1991). El pan de cada día: el mercado del trigo en Buenos Aires, 1700-1820. Boletín del Instituto de Historia Argentina y Americana Dr. E. Ravignani, $3(4), 7-29$.

Garavaglia, J. C. (1999). Pastores y labradores de Buenos Aires. Buenos Aires: Ediciones de la Flor.

GARCíA, C. (1986). Haciendas municipales y bienes de propios: las reformas de Carlos III. Anales de Estudios Económicos y Empresariales, 1, 89-114. Recuperado de https:// dialnet.unirioja.es/servlet/articulo?codigo $=785131$

Gelman, J. (2005). Derechos de propiedad: crecimiento económico y desigualdad en la región pampeana, siglos XVIII y XIX. Revista Historia Agraria, 37, 467-488. Recuperado de http://www.historiaagraria.com/articulo.php?id=396\&num=37

Jumar, F. (2000). Le commerce atlantique au Río de la Plata, 1680-1778 (Tesis doctoral). École des Hautes Études en Sciences Sociales, París, Francia. Recuperado de http:// www.fuentesmemoria.fahce.unlp.edu.ar/tesis/te.364/te.364.pdf

LLOPIS, E. y MARICHAL, C. (2009). Latinoamérica y España, 1800-1850. Un crecimiento económico nada excepcional. España: Marcial Pons/Instituto de Investigaciones Dr. José María Luis Mora.

MárQuez, G. (coord.) (2014). Claves de la historia económica de México. El desempeño de largo plazo, siglos XVI-XXI. México: Fondo de Cultura Económica.

MartíneZ, M. (1997). El municipio controlado. Los reglamentos de propios y arbitrios en las reformas carolinas. América Latina en la Historia Económica, 4(7), 9-17. DOI: 10.18232/alhe.v4i07.198

Rosal, M. y Schmit, R. (2004). Las exportaciones pecuarias bonaerenses y el espacio mercantil rioplatense. En R. Fradkin y J. C. Garavaglia, En busca de un tiempo 
perdido. La economía de Buenos Aires en el País de la abundancia, 1750-1865 (pp. 159194). Buenos Aires: Prometeo.

SÁnchEZ, E. (2011). El peso de la fiscalidad sobre la economía mexicana, 1790-1910. Historia Mexicana, 61(1), 107-162. Recuperado de http://historiamexicana.colmex. $\mathrm{mx} /$ index.php/RHM/article/view/280

SAntos, P. (1974). Historia económica de Mendoza durante el virreinato, 1776-1810. Madrid/Mendoza: Instituto Gonzalo Fernández de Oviedo/Universidad Nacional de Cuyo.

Silva, J. (2015). La reforma fiscal de los ayuntamientos novohispanos (1765-1812). Madrid: Marcial Pons.

Thompson, E. P. (1995). Costumbres en común. Barcelona: Crítica.

Torres, R. (2013). El precio de la guerra. El Estado fiscal-militar de Carlos III (1779-1783). Madrid: Marcial Pons.

\section{Archivos}

AGN Archivo General de la Nación, Buenos Aires, Argentina.

AEcBA Acuerdos del Extinguido Cabildo de Buenos Aires, Argentina.

AHPBA Archivo Histórico de la Provincia de Buenos Aires, Argentina. 